\title{
Low Birth Weight at Term: Risk Factors and Perinatal Prognosis in the Teaching Hospital Yalgado Ouédraogo, Burkina Faso
}

\author{
Dantola Paul Kain ${ }^{*}$, Adama Ouattara1, Hyacinthe Zamané1, Sibraogo Kiemtoré1, \\ Issa Ouédraogo ${ }^{2}$, Yobi Alexis Sawadogo ${ }^{1}$, Ali Ouédraogo ${ }^{1}$, Blandine Thiéba ${ }^{1}$ \\ ${ }^{1}$ Teaching Hospital Yalgado Ouédraogo, Ouagadougou, Burkina Faso \\ ${ }^{2}$ Teaching Hospital Ouahigouya, Ouahigouya, Burkina Faso \\ Email: *zanlotoma@yahoo.fr
}

How to cite this paper: Kain, D.P., Ouattara, A., Zamané, H., Kiemtoré, S., Ouédraogo, I., Sawadogo, Y.A., Ouédraogo, A. and Thiéba, B. (2018) Low Birth Weight at Term: Risk Factors and Perinatal Prognosis in the Teaching Hospital Yalgado Ouédraogo, Burkina Faso. Open Journal of Obstetrics and Gynecology, 8, 1510-1519. https://doi.org/10.4236/ojog.2018.814152

Received: November 14, 2018 Accepted: December 10, 2018 Published: December 13, 2018

Copyright $\odot 2018$ by authors and Scientific Research Publishing Inc. This work is licensed under the Creative Commons Attribution International License (CC BY 4.0).

http://creativecommons.org/licenses/by/4.0/

\begin{abstract}
Objective: The objective of our study was to study the risk factors of low birth weight at term in the Teaching Hospital Yalgado (CHU-YO) Ouédraogo. Patients and Methods: This dealt with a comparative and analytical control case study. The group of cases was made up of female patients who gave birth to newborns with low birth weight at term and that of control cases included female patients who delivered a normal-weighted newborn at term. Results: The frequency of low birth weight at term was therefore estimated at $4.4 \%$. The average age of the parturients was $25 \pm 6.36$ years. Female patients living in a marital setting accounted for $93.1 \%$ of cases and $64.4 \%$ of them had no income-generating activities. A maternal underweight, a height below $155 \mathrm{~cm}$, passive smoking, and malaria during pregnancy have been identified as the factors associated with a low birth weight. Conclusion: Quality prenatal care could reduce the incidence of low birth weight at term.
\end{abstract}

\section{Keywords}

Low Birth Weight, Risk Factors, Prognosis, Burkina Faso

\section{Introduction}

Low birth weight is a global health issue which affects both developed and developing countries. According to data from WHO and UNICEF published in 2004 , the global percentage of low birth weight was estimated at $15.5 \%$, corresponding to more than 20 million children [1].

Low birth weight is due to a preterm delivery, to intra uterine growth retardation or to a combination of both. In developed countries, prematurity is the 
main etiology of low birth weight while in developing countries, it is intra uterine growth retardation [2] [3].

Low birth weight contributes to about $60 \%-80 \%$ of the overall neonatal deaths [4]. It is also associated with childhood stunting, to delayed cognitive development, and chronic diseases [1] [5] [6].

Considering the importance of the low birth weight issue, the following question is relevant: What are the low birth weight determinants at full term?

In Burkina Faso, a case-control study implemented in 2004 within eight maternities in Ouagadougou had pointed out the nutritional status of the mother [7] as a major determinant. This study has admitted premature infants or used morphological criteria to determine the gestational age.

This study brings inputs to the knowledge of the determining factors related to low birth weight at term, and more particularly the intra uterine growth retardation among the newborns at full term, as several methods have been used. Indeed, the newborns with low birth weight and at term (based on the existence of dated ultrasound) were selected in order to eliminate the prematurity effects on birth weight.

\section{Patients and Methods}

This deals with an analytical and comparative control case study. The group of cases included female patients who gave birth to a newborn with low birth weight at term and that of control group, those who gave birth to a newborn with normal weight at term. The ratio was $1 / 1$. Cases and control cases were recruited during the period 11/1/2015 to 03/06/2016.

The population of study involved all the parturients admitted in the department of Gynecology and Obstetrics of CHU-YO during the concerned period.

The following formula was used to determine our sample size:

$$
N=P \times(1-P) \times Z \alpha / i^{2}
$$

$P$ means the proportion of newborns with a low birth weight at term. According to EDS IV (Demographic and Health Survey), low birth weight in Burkina Faso is estimated at $14 \%$ among which $1 / 5$ occurs among the newborns with a low birth weight at term. Therefore, the proportion of newborns with a low birth weight is estimated at $2.8 \%$ [8].

$$
P=2.8 \%
$$

$Z \alpha=1.96$ the value of $Z$ for a risk of error alpha, $\alpha=0.05$

$i$, desired precision $=5 \%$

$$
N=0.028 \times(1-0.028) \times 1.96^{2} / 0.05^{2}=41.82
$$

The minimal size of our sample is at least 42 cases and 42 control cases.

Female parturients meeting the following criteria and admitted in the site of the study during the period of the survey were included in the group of cases: single pregnancy, theoretical term of 37 weeks of amenorrhea evidenced by the first quarter ultrasound, having given birth to a newborn whose weight is below 
$2500 \mathrm{~g}$, verbal agreement to take part to the study. The control cases had the same criteria except for the birth weight which was equal or higher than $2500 \mathrm{~g}$.

The control group was formed by matching the cases. The maternal age was the matching criteria. Then, any parturient of a given age in the group of cases was systematically matched with another one of the same age who gave birth to a newborn with a normal weight.

The variables studied were the following: socio-demographic characteristics of patients and the pregnancy follow-up elements.

As for the socio-economic level: we have developed a socio-economic score level based on that of WHO.

Presence of running water (yes $=1$, no $=0$ ), of electricity (yes $=1$, no $=0$ ), occupation of the person taking care of the woman (civil servant category $\mathrm{A} / \mathrm{B} / \mathrm{C}$, tradesman $=3$; civil servant category $\mathrm{D} / \mathrm{E}$, small merchant, craft worker $=2$; farmer, street vendor, no activity $=1$ ), woman's occupation (civil servant category $\mathrm{A} / \mathrm{B} / \mathrm{C}$, tradeswoman $=3$; civil servant category $\mathrm{D} / \mathrm{E}$, small merchant, craft worker $=2$, farmer, street vendor, no activity $=1)$. The total score is estimated at 8 .

Score $<3$ = low socio-economic level

Score $3-7$ = average socio-economic level

Score $>7$ high socio-economic level

As for the stress level: we have developed an inspired score using the physical signs of stress at the burnout phase. The parturients with the following characteristics (yes $=1+2+3$ ) were considered as stressed:

1) Persisting tiredness after a night sleep, irritability, nervousness, tension, anger

2) Anxiety (events that are not distressing in normal times);

3) Depression (lack of motivation), insomnia, pessimism.

Intense physical works were assessed according to the following characteristics (yes $=1$ or 2 or 3 ):

1) Professional activity requiring physical effort (farmer, tradeswoman making many trips) or prolonged standing position (in teaching);

2) Long distanced travelled every day by foot or bicycle

3) Tiring household chores (fetching water, breaking wood, pounding, daily clothes washing)

The information was collected through the baby delivery record, the admission register, the patients' medical records, the parturients' prenatal consultations handbook and questions asked to them.

EPIDATA ANALYSIS was the software used to analyze the data. The odds ratio and $\mathrm{p}$ value were calculated and compared through the chi-square test. The significance threshold selected in the analyses reached $5 \%$.

\section{Results}

\subsection{Frequency}

1975 live births were reported during the period of study among which we have 
noted 87 cases of low birth weight. The frequency of low birth weight was therefore estimated at $4.4 \%$.

\subsection{Description of Female Patients Who Gave Birth to a Newborn with a Low Birth Weight at Term}

\section{- Socio-demographic characteristics}

The average age of the parturients was $25 \pm 6.36$ years with extremes of 15 and 42 years. Patients living in a marital setting accounted for $93.1 \%$ of cases and $64.4 \%$ of cases had no income-generating activities. $71.3 \%$ of cases had a low socio-economic status and $44.8 \%$ of them have not attended school. Alcohol consumption during pregnancy and passive smoking were found in respectively $6.9 \%$ and $18.4 \%$ of cases. Primiparous women accounted for $50.6 \%$ of cases.

\section{- Prenatal follow-up}

Prenatal follow-up was normal in terms of the number of prenatal consultations performed, of anti-malaria and anti-anemia chemoprophylaxis. The pathological episodes during pregnancy were represented by severe vomiting, episodes of malaria and a pre-eclampsia in respectively $11.5 \%, 33.3 \%$ and $9.2 \%$ of cases.

\section{- Anthropometric data}

$31 \%$ of patients had a height below $155 \mathrm{~cm}$ and $9.7 \%$ of them were thin in their pregnancy beginning (a body mass index inferior to $18 \mathrm{~kg} / \mathrm{m}^{2}$ ).

\subsection{Study of Risk Factors Associated to Low Birth Weight at Term}

The risk factors are outlined in the Tables 1-3.

We had searched risk factors associated to low birth weight at term among socio-demographic characteristics of patient and among prenatal follow-up. We had found that severe low weight (body mass index less than $18 \mathrm{~kg} / \mathrm{m}^{2}$ ), number of prenatal follow-up less than 3, height less than $155 \mathrm{~cm}$, high level of stress, passive smoking, malaria during the pregnancy, were associated to low birth weight at term.

\subsection{Perinatal Prognosis}

14.9\% of the newborns with a low birth weight had an Apgar score below 7 at the first minute. The newborns transferred in neonatology department accounted for $19.5 \%$ of cases.

Unfortunately, one neonatal death has been reported.

\section{Discussion}

\subsection{Frequency}

We limited the study to low birth weight at term to eliminate low birth weight cases related to prematurity. The low birth weight frequency found at the maternity of CHU/YO was $12.86 \%$. This figure is slightly below the one reported by the Demographic and Health Survey (EDS) estimated at $14 \%$ for the whole 
country [8] and below that of Nikièma'study conducted in 2005 in Ouagadougou which reached $14.6 \%$ [7]. This difference could be explained by the fact that the study carried out through the EDS has concerned the whole country while Nikièma has only collected data in eight maternities. However, this frequency is close to that of a study conducted in Bobo Dioulasso in 1993, which found a proportion of $12.94 \%$ [9].

Table 1. Risk factors related to socio-demographic characteristics $\left(n=87 ; n^{\prime}=87\right)$.

\begin{tabular}{|c|c|c|c|c|}
\hline $\begin{array}{l}\text { Socio-demographic } \\
\text { characteristics }\end{array}$ & $\begin{array}{l}\text { Cases } \\
(\%)\end{array}$ & $\begin{array}{c}\text { Control-cases } \\
(\%)\end{array}$ & OR (IC 95\%) & $\begin{array}{l}\text { P global } \\
\text { value }\end{array}$ \\
\hline \multicolumn{5}{|l|}{ Marital status } \\
\hline Unmarried & $6(6.89)$ & $5(5.74)$ & $1.47(0.37-5.47)$ & 0.690 \\
\hline Married & $81(93.1)$ & $82(94.25)$ & $1.37(0.67-2.57)$ & \\
\hline \multicolumn{5}{|l|}{ Occupation } \\
\hline No activity & $56(64.36)$ & $48(55.17)$ & $1.46(0.79-2.69)$ & 0.586 \\
\hline Activity & $31(35.63)$ & $39(44.82)$ & & \\
\hline \multicolumn{5}{|l|}{ Economic status } \\
\hline Low & $62(71.26)$ & $66(75.85)$ & $0.78(0.40-1.55)$ & 0.462 \\
\hline Average & $23(26.43)$ & $20(22.98)$ & & \\
\hline High & $2(2.29)$ & $1(1.14)$ & & \\
\hline \multicolumn{5}{|l|}{ Educational level } \\
\hline Did not attend school & $39(44.82)$ & $35(40.22)$ & $1.20(0.66-2.24)$ & 0.665 \\
\hline Attended school & $48(55.17)$ & $52(59.97)$ & & \\
\hline \multicolumn{5}{|l|}{ Stress level } \\
\hline High & $16(18.39)$ & $6(6.89)$ & $3.36(1.22-9.21)$ & 0.043 \\
\hline average & $21(24.41)$ & $18(20.68)$ & $1,47(0.70-3.05)$ & \\
\hline Low & $50(57.47)$ & $63(72.41)$ & & \\
\hline \multicolumn{5}{|l|}{ Physical works } \\
\hline Yes & $32(36.78)$ & $23(26.43)$ & $1.67(0.84-3.08)$ & 0.103 \\
\hline No & $35(40.22)$ & $64(73.56)$ & & \\
\hline \multicolumn{5}{|l|}{ Alcohol consumption } \\
\hline Yes & $6(6.89)$ & $5(5.74)$ & $1.21(0.36-4.14)$ & 0.755 \\
\hline No & $81(93.1)$ & $82(94.25)$ & & \\
\hline \multicolumn{5}{|l|}{ Passive smoking } \\
\hline Yes & $16(18.39)$ & $7(8.04)$ & $\begin{array}{c}2.57(1.002- \\
6.01)\end{array}$ & 0.04 \\
\hline No & $71(81.6)$ & $80(91.95)$ & & \\
\hline
\end{tabular}


Table 2. Risk factors related to prenatal follow-up $\left(n=87 ; n^{\prime}=87\right)$.

\begin{tabular}{|c|c|c|c|c|}
\hline Prenatal follow-up & $\begin{array}{c}\text { Cases n } \\
(\%)\end{array}$ & $\begin{array}{c}\text { Control cases } n^{\prime} \\
(\%)\end{array}$ & OR IC (95\%) & $P$ value \\
\hline \multicolumn{5}{|l|}{$\begin{array}{c}\text { Number of PC } \\
\text { (prenatal consultations) }\end{array}$} \\
\hline$<3$ & $23(26.43)$ & $6(6.89)$ & $4.96(1.81-13.53)$ & 0.002 \\
\hline$\geq 3$ & $64(73.56)$ & $81(93.1)$ & & \\
\hline \multicolumn{5}{|c|}{ antimalarial chemoprophylaxis } \\
\hline Yes & $81(46.6)$ & $87(100)$ & 0 (inf - inf) & \\
\hline No & $6(3.4)$ & $0(100)$ & & \\
\hline \multicolumn{5}{|c|}{ anti-anemia chemoprophylaxis } \\
\hline Yes & $82(47.1)$ & $87(100)$ & 0 (inf - inf) & \\
\hline No & $5(2.9)$ & $0(0)$ & & \\
\hline \multicolumn{5}{|c|}{ Significant severe vomiting } \\
\hline Yes & $10(11.49)$ & $3(3.44)$ & $3.64(0.96-13.7)$ & 0.043 \\
\hline No & $77(88.50)$ & $84(96.55)$ & & \\
\hline \multicolumn{5}{|l|}{ Malaria } \\
\hline Yes & $29(33.33)$ & $16(18.39)$ & $2.22(1.10-4.48)$ & 0.024 \\
\hline No & $58(66.67)$ & $71(81.60)$ & & \\
\hline \multicolumn{5}{|l|}{ Pre-eclampsia } \\
\hline Yes & $8(9.19)$ & $6(6.89)$ & $1.37(0.45-4.12)$ & 0.577 \\
\hline No & $79(90.80)$ & $81(93.10)$ & & \\
\hline \multicolumn{5}{|l|}{ IMC (body mass index) } \\
\hline$<18 \mathrm{~kg} / \mathrm{m}^{2}$ & $6(9.67)$ & $0(0)$ & $\begin{array}{c}<8.81(1.02- \\
7.52)\end{array}$ & 0.0044 \\
\hline$>18 \mathrm{~kg} / \mathrm{m}^{2}$ & $56(90.32)$ & $75(0.96)$ & & \\
\hline Total & $62(100)$ & $75(100)$ & & \\
\hline \multicolumn{5}{|l|}{ Height } \\
\hline$<155 \mathrm{~cm}$ & $27(31.03)$ & $8(9.19)$ & $4.44(1.89-10.47)$ & 0.0003 \\
\hline$\geq 155 \mathrm{~cm}$ & $60(68.96)$ & $79(90.80)$ & & \\
\hline
\end{tabular}

Table 3. Risk factors of low birth weight at term.

\begin{tabular}{ccc}
\hline Risk factors & OR & P value \\
\hline Severe low weight during the first quarter Body mass index $<18 \mathrm{~kg} / \mathrm{m}^{2}$ & $<8.81$ & 0.0044 \\
Number of prenatal follow-up $<3$ & 4.96 & 0.002 \\
Height $<155 \mathrm{~cm}$ & 4.44 & 0.0003 \\
High level of stress & 3.36 & 0.043 \\
Passive smoking & 2.57 & 0.040 \\
Malaria during the pregnancy & 2.22 & 0.024 \\
\hline
\end{tabular}




\subsection{Risk Factors of Low Birth Weight at Term}

\section{Socio-economic level}

Parturients with no schooling and with no professional activity were slightly but not significantly associated with low birth weight while those having a low economic level were not associated. Nikièma [7] and Tambwe [10] go in the same trend; however, the low economic level was slightly but significantly associated with low birth weight in their studies. The matching we made has probably reduced the differences between the cases and control cases, which may explain the fact that the low economic level has not been identified as a risk factor for low birth weight at term in our study.

\section{- Social environment}

Among the social environment characteristics, the level of stress has been identified as a risk factor for a low birth weight at term. This matches with literature data. The patients subject to a high stress level were typically anorexic because of health and social problems encountered during their pregnancy.

Passive smoking during pregnancy also increases by almost twice the risk of low birth weight. This significant relation is found in the studies of Hortal B L et al. [11] and Fourn L. [12] where passive smoking and smoking increase the risk of low birth weight. Nikièma et Kaboré [7] [13] have not identified this type of relation. Tobacco and nicotine bring about a decrease in the placental uterine flow which causes insufficient nutritional intake for fetal growth. There is a dose-response effect regarding smoking and low birth weight [11]. Only passive smoking was taken into account in our analysis because none of our patients consume tobacco.

\section{Prenatal follow-up}

\section{- Maternal body weight}

We notice that the risk of giving birth to a child of low weight is about eight times higher when the body mass index is inferior to $18 \mathrm{~kg} / \mathrm{m}^{2}$. The risk is four times higher when such index is between 18 and $19.99 \mathrm{~kg} / \mathrm{m}^{2}$. Several studies such as those of Nikèma [7], Somé [9], Tambwe [10], Mafina-Mienandi et al. [14], Ronnenberg and al [15] have established this significant relation between low body mass index during pregnancy and low birth weight. Thus, maternal nutritional intake during pregnancy contributes to meeting the mother's energy needs as well as the fetus 'growth and energy needs. An intake below 1500 $\mathrm{cal} /$ day and a low weight gain during the third trimester is more likely to result in a fetal weight reduction [15].

\section{- Height}

Parturients whose height is smaller than $155 \mathrm{~cm}$ are four times more likely to have babies with low birth weight. This situation can be observed in other studies [7] [9] [10]. Indeed, a small-heighted pregnant woman has a reduced or small volume of systolic cardiac ejection that leads to a decrease in utero placental perfusion with deficient transfer of nutrients from the pregnant woman to the fetus, thus causing intrauterine growth retardation. 


\section{- The number of prenatal cares}

A number of prenatal cares below three increases by almost five times the risk of giving birth to a baby with a low birth weight. Other studies [7] [14] and [16] have also found this correlation. Prenatal consultation enables to identify and treat the pathologies which may occur during the pregnancy and to improve both mother' and fetus' wellbeing.

\section{- Pathologies during the pregnancy}

A history of malaria during pregnancy increases by twice the risk of low birth weight. This significant association is found in the studies of Tambwe [10], Matteelli A et al. [17], and Allen SJ et al. [18]. Malaria infection causes the destruction of the red blood corpuscles responsible for anemia and the fetus nutritional defect. In addition, Sullivan AD et al. [19] have found an increase of TNF-alpha or IL-8 expression in the placenta which was associated with intrauterine growth retardation. These results suggest that malaria infections induce a potentially harmful pro-inflammatory response in the placenta [3] [19].

\section{Conclusion}

This study identified risk factors associated to low birth weight at term. We must take action to reduce the impact of these factors. Quality prenatal care is likely to reduce the incidence of low birth weight at term.

\section{Conflicts of Interest}

The authors declare no conflicts of interest regarding the publication of this paper.

\section{References}

[1] United Nations Children's Fund and World Health Organization. Low Birthweight: Country, Regional and Global Estimates. UNICEF, New York, 2004.

[2] Villar, J.B.J. (1982) The Relative Contribution of Prematurity and Fetal Growth Retardation to Low Birth Weight in Developing and Developed Societies. American Journal of Obstetrics and Gynecology, 143, 793-798. https://doi.org/10.1016/0002-9378(82)90012-6

[3] Menendez, C., Ordi, J., Ismail, M.R., Ventura, P.J., Aponte, J.J., Kahigwa, E., et al. (2000) The Impact of Placental Malaria on Gestational Age and Birth Weight. The Journal of Infectious Diseases, 181, 1740-1745. https://doi.org/10.1086/315449

[4] OMS (2015) Programmes et projets. Santé de la mère, du nouveau-né de L'Enfant ET de l'adolescent [In English: WHO (2015) Programs and Projects. Maternal, Newborn, Child and Adolescent Health] http://www.who.int/maternal_child_adolescent/topics/newborn/care_of_preterm/fr/

[5] Ouédraogo, S.P. (2013) Impact du faible poids de naissance sur la croissance, le développemnt psychomoteur et la morbidité au cours des trois premiers mois de vie à Bobo Dioulasso. Thése médecine Université Polytechnique de Bobo, No. 002, $90 \mathrm{p}$ [In English: Ouédraogo, S.P. (2013) Impact of Low Birth Weight on the Growth, the Psychomotor Development and Morbidity during the First Three Months of Life in Bobo. Thesis in Medical Studies of the Polytechnic University of Bobo, No. 002, 90 
p]

[6] Pollitt, E., Gorman, K.S., Engle, P.L., Rivera, J.A. and Martorell, R. (1995) Nutrition in Early Life and the Fulfillment of Intellectual Potential. Journal of Nutrition, 125, 1111S-1118S

[7] Nikièma, L.O. (2005) Facteurs de risques associés au RCIU, étude cas témoins dans la ville de Ouagadougou. Mémoire, Université Pierre et Marie Curie, 31 p. [In English: Nikièma, L.O. (2005) Risk Factors Associated to RCIU, Control Cases Study in the Town of Ouagadougou. Dissertation. University Pierre et Marie Curie, $31 \mathrm{p}]$

[8] Institut National de la Statistique et de la Démographie (INSD) et ICF International (2012) Enquête Démographique et de Santé et à Indicateurs Multiples du Burkina Faso 2010. INSD et ICF International, Calverton. [In English: Institut National de la Statistique et de la Démographie (INSD) and ICF International (2012) Demographic and Health Survey and Multiple Indicators of Burkina Faso 2010. INSD et ICF International, Calverton]

[9] Some, D.A. (1993) Le faible poids de naissance: Facteurs de risques en milieu urbain de Bobo Dioulasso. Thèse médecine, Université de Ouagadougou, No. 5. [In English: Some, D.A. (1993) Low Birth Weight: Risk Factors in Urban Areas of Bobo Dioulasso. Thesis in Medical Studies, University of Ouagadougou, No. 5]

[10] Tambwe, A.M., Ngwe, J., Moyamb, T., et al. (2013) Etude des facteurs de risques du RCIU à Lubumbashi. Pan African Medical Journal, 14, 4. [In English: Tambwe, A.M., Ngwe, J., Moyamb, T., et al. (2013) Study of Risk Factors of RCIU in Lubumbashi. Pan African Medical Journal, 14, 4]

[11] Horta, B.L., Victora, C.G., Menezes, A.M., Halpern, R. and Barros, F.C. (1997) Low Birthweight, Preterm Births and Intrauterine Growth Retardation in Relation to Maternal Smoking. Paediatric and Perinatal Epidemiology, 11, 140-151. https://doi.org/10.1046/j.1365-3016.1997.d01-17.x

[12] Fourn, L., Ducic, S. and Seguin, L. (1999) Smoking and Intrauterine Growth Retardation in Republic of Benin. Journal of Epidemiology and Community Health, 53, 432-433. https://doi.org/10.1136/jech.53.7.432

[13] Kaboré, P., Donnen, P. and Dramaix-Wilmet, M. (2007) Facteurs de risques obstétricaux du petit poids de naissance à terme en milieu sahélien. Revue de Santé Publique, 19, 489-484. [In English: Kaboré, P., Donnen, P. and Dramaix-Wilmet, M. (2007) Obstetrical Factors of Low Birth Weight at Term within a Sahelian Context]

[14] Mafina-Mienandi, M.C., Ganga-Zandzou, P.S., Makoumbou, P., Malonga, H., Ekoondzola, J.R. and Mayanda, H.F. (2002) Facteurs de risques du retard de croissance intra utérin au Congo. Journal de Gynécologie Obstétrique et Biologie de la Reproduction, 31, 500-505. [In English: Mafina-Mienandi, M.C., Ganga-Zandzou, P.S., Makoumbou, P., Malonga, H., Ekoondzola, J.R. and Mayanda, H.F. (2002) Risk Factors of Intrauterine Growth Retardation in Congo. Journal of Gynecology $\mathrm{Ob}$ stetrics and Human Reproduction, 31, 500-505]

[15] Ronnenberg, A.G., Wang, X., Xing, H., et al. (2003) Low Preconception Body Mass Index Is Associated with Birth Outcome in a Prospective Cohort of Chinese Women. Journal of Nutrition, 133, 3449-3455. https://doi.org/10.1093/in/133.11.3449

[16] Ferraz, E.M., Gray, R.H. and, Cunha, T.M. (1990) Determinants of Preterm Delivery and Intrauterine Growth Retardation in North-East Brazil. International Journal of Epidemiology, 19, 101-108. https://doi.org/10.1093/ije/19.1.101

[17] Matteelli, A., Donato, F., Shein, A., et al. (1996) Malarial Infection and Birthweight in Urban Zanzibar, Tanzania. Annals of Tropical Medicine \& Parasitology, 90, 
125-134. https://doi.org/10.1080/00034983.1996.11813036

[18] Allen, S.J., Raiko, A., O’Donnell, A., Alexander, N.D. and Clegg, J.B. (1998) Causes of Preterm Delivery and Intrauterine Growth Retardation in a Malaria Endemic Region of Papua New Guinea. Archives of Disease in Childhood Fetal and Neonatal Edition, 79, F135-F140. https://doi.org/10.1136/fn.79.2.F135

[19] Sullivan, A.D., Nyirenda, T., Cullinan, T., et al. (1999) Malaria Infection during Pregnancy: Intrauterine Growth Retardation and Preterm Delivery in Malawi. The Journal of Infectious Diseases, 179, 1580-1583. https://doi.org/10.1086/314752 